Int. J. Electrochem. Sci., 14 (2019) $3024-3034$

\title{
Synthesis Metal-free Nitrogen-doped Porous Carbon by Removing Al from Al-MOFs as an Efficient Electrocatalyst for Oxygen Reduction Reaction
}

\author{
Yan Zhang ${ }^{1, \dagger}$, Yu Zhou ${ }^{1, \dagger}$,Zonghua Wang ${ }^{*}, 1$, Shenlong Zhao ${ }^{2}$, Chunhui Tan ${ }^{3}$ and Jishi Chen ${ }^{1}$ \\ ${ }^{1}$ Shandong Sino-Japanese Center for Collaborative Research of Carbon Nanomaterials, College of \\ Chemistry and Chemical Engineering, Qingdao University, Qingdao 266071, China. \\ ${ }^{2}$ UNSW-CWRU International Joint Laboratory, School of Chemical Engineering, the University of \\ New South Wales, Sydney, NSW 2052, Australia. \\ ${ }^{3}$ Key Laboratory for Biomass Gasification Technology of Shandong Province, Energy Research \\ Institute, Qilu University of Technology (Shandong Academy of Sciences), Jinan, 250014, China \\ $\dagger$ These authors contributed equally to this work \\ *E-mail: wangzonghua@qdu.edu.cn
}

doi: $10.20964 / 2019.03 .27$

Received: 27 October 2018 / Accepted: 17 December 2018 / Published: 7 February 2019

Exploring cheap and stable electrocatalyst for the oxygen reduction reaction (ORR) is now an important issue for the large-scale application of fuel cells. Herein, we have demonstrated a facile synthesis of Nitrogen-doped porous carbons (NPC-MILs) for oxygen reduction reaction by using an amine functionalized Al-MOFs $\left(\mathrm{NH}_{2}-\mathrm{MIL}-53(\mathrm{Al})\right.$ ) as the precursor with both nitrogen source and carbon source. NPC-MILs as metal-free electrocatalysts are demonstrated promising potential for ORR. The optimized NPC-MIL-900 (carbonized at $900{ }^{\circ} \mathrm{C}$ ) exhibits a likeness four-electron process and its ORR catalytic activity can be comparable to commercial Pt/C. Furthermore, chronoamperometric measurement shows that only $13 \%$ loss at the current density is occurred after $40000 \mathrm{~s}$, whereas the corresponding current density loss at the $\mathrm{Pt} / \mathrm{C}(20 \mathrm{wt} \%)$ is as high as $31 \%$. Chronoamperometric responses also show the NPC-MIL-900 catalyst has higher resistance to methanol in alkaline electrolyte than Pt/C. Those indicate that the NPC-MIL-900 has potential application in fuel cells.

Keywords: electrocatalyst, metal-free, oxygen reduction reaction, N-doped microporous carbon material, metal-organic framework

\section{$\underline{\text { FULL TEXT }}$}

(C) 2019 The Authors. Published by ESG (www.electrochemsci.org). This article is an open access article distributed under the terms and conditions of the Creative Commons Attribution license (http://creativecommons.org/licenses/by/4.0/). 
